\title{
Security and Automation of Society Model Based on Advance Technology of Artificial Intelligence
}

\author{
Aakash Tappe ${ }^{1}$, Advita Dalal ${ }^{1}$, Akshay Tembhurne ${ }^{1}$, Samiksha Patil ${ }^{1}$, Snehankit Katkar ${ }^{1}$, Prof. Merajul Haque Farooqi ${ }^{2}$ \\ ${ }^{1}$ UG Students, Department of Information Technology, JD College Of Engineering and Management, Nagpur, Maharashtra, \\ India \\ ${ }^{2}$ Assistant Professor, Department of Information Technology, JD College Of Engineering and Management, Nagpur, \\ Maharashtra, India
}

\begin{abstract}
The world is changing not only because of people's way of thinking but also the increasing innovative technology. At first which seemed impossible is now both possible and safer. The enhanced technology has helped us make our life happier, better, faster and even safer. Increasing enriching technology is creating new era for science, medicine, luxury and many more things. We have witnessed progressing innovations which are helping us deal with the things human alone can't deal with! As of the current scenario we are already aware of and that is the pandemic: covid-19. Due to the recent scenario of pandemic, things have gotten pretty different. Some may have adapted to it and living accordingly while others are still in the state of fear. The only pillar standing between the illness and healthiness is "taking precautions". . If we want to get out of the state of the fear and live peacefully again in worse cases possible, it will always be necessary to take all the necessary precautions.
\end{abstract}

Index Terms: Internet of Things (IoT), Raspberry Pi, Pi camera, PIR sensor.

\section{INTRODUCTION}

The smart technology is the term every industry is using may it be food industry, education industry or entertainment industry. Now, the world is only a step away to create the imaginary concept come into reality, the term "magic" now can be seen and experience because of the use of technology. If we take it one way or other, the technology itself is a "Magic", a magic which is making us advanced, faster and helping us create a better tomorrow. Human life getting simpler and simpler because the technology is serving as a bridge between the dreams and reality, as they say: everything is just a touch away.

Yet the only terms we are lacking in is controlling the increasing diseases and illness is spreading faster than even the growing technology. Although, constant efforts are being made to win over the illness. And as of the current scenario of Covid-19, it has again proved that the world is indeed a smaller place when it comes to reinventing something or even spreading disease like Covid-19 in just a blink. This pandemic has taught us

Volume 23, Issue 4, April - 2021 various lessons and the top highlight is even the high transmission rate diseases can be prevented only by practicing hygiene, healthy lifestyle and taking the precautions.

Nowadays, Home Automation is trending topic all over the world. In the times like this i.e. pandemic, the world suffers more and it requires more resources to keep everyone safe. "The safety has and will always be the first priority". Now, because of technology everything has become just one touch away. Though it has both benefits and non-benefits for the nature and people; there's no stopping increasing technology. In this paper, we will be discussing about an idea which is concern with the safety.

Let's focus on the current scenario of Covid-19, the only precautions which will help the world is taking precautions. We all are aware of what the necessary precautions are! However, we try but there will always be the chances of getting affected by even a little negligence. We can dive in more deep to see how a little ignorance can be extremely harmful. Allow me to present a scenario before you. The pandemic hasn't ended yet and the most important tip to follow is "Maintain social distance, wear mask and wash your hands". Suppose you live in a big society consisting 7 Building Blocks, and it has a common entrance. A family living in the building block $\mathrm{D}$ on floor 5 has ordered a food dish online. After 30 mins, a delivery boy appears on the entrance gate. As he approaches towards the entrance, the watchman interrupts him and asks him to wear his mask because he wasn't wearing one. The delivery boy wears the mask as instructed by the watchman. Delivery boy moves forward but again gets interrupted by the watchman asking for permission to check the body temperature. After checking the temperature, if normal then the watchman allows him to proceed towards block D only after he uses sanitizer and cleans his hands.

The delivery boy has reached the block D parking area and moves forward towards the lift. He then presses the button 5 inside the lift. The $5^{\text {th }}$ floor has arrived and he gets out of the lift, moves towards the flat no. He rings the bell and lowers his face mask. A family member opens the door and sees that he is not wearing the mask. A family member receives a parcel and after the delivery boy leaves, he calls the watchman to 
complain about "the delivery boy not wearing mask and HomeKit," expected to provide voice support as a hub to jeopardising society members' safety". As discussed control home kit products [6]. Thus, smart home services above, we know this wasn't the fault of Watchman are developing and proliferating by adopting IoT and AI. because he had already instructed delivery boy to wear the Prior studies on smart homes are based on a technical or a mask.

partial approach. For instance [7] suggested a smart floor

In this paper, we present a security and automation technology for a smart home which examines who, where, of society model based on advance technology of artificial and what a user is doing.

intelligence. The system designed is Security and automation society consist of PIR censor, Raspberry Pi and Pi Camera.

\section{LITERATURE REVIEW}

A smart home refers to a residence equipped with a communication network, high-tech household devices, appliances, and sensors that can be remotely accessed, monitored, and controlled and that provide services responding to the residents' needs [1].

Although the widespread diffusion of high-speed Internet in the late 1990s provided the opportunity for the home network business to grow, it was not until the late 2000s that smart homes began to be installed, which is when smart phones were popularized. Initially, a smart home was defined using various names, such as a home network, a digital home, home automation, and an intelligent home. In the mid-2010s, it has been leaning towards a combination of Internet of Things (IoT) and a situationaware smart home. A smart home is an advanced form of traditional home automation. An early definition of a smart home, which was influenced by home automation, is using common communication devices to integrate with a variety of services at home, assuring economic, secure, and comfortable operation of the home [2].

Thus, smart home service was used to manage environmental systems like lighting and heating. These days due to technological development, a smart home service monitors user activities and the internal environment at home [3]. Moreover, a smart home provides services that fulfil the demands and needs of a user. Recently, smart home services are evolving as they approach artificial intelligence [4].

The intelligent personal assistant "Alexa," developed by Amazon Lab126, has been installed in a wide range of products. LG Electronics has adopted Alexa throughout its smart home product line. For example, if a user calls "Alexa" from a smart refrigerator, the user can access services such as searching news, online shopping, and checking schedules [5].

In addition, China smart home manufacturer Xiaomi is planning to target the smart home market as part of its long-term vision. Xiaomi launched an air purifier that can be remotely controlled by a smart phone and developed a smart module that can be inserted into all appliances such as refrigerators, air conditioners, and washing machines.

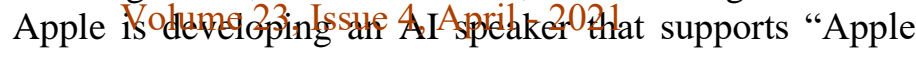

Adami et al. [8] proposed a wrist gadget that monitors users' habits at home. Andoh et al. In [9], suggested a biometrics monitoring system for analyzing the pulse and respiratory rate at home.

Koskela and Väänänen-Vainio-Mattila [10] conducted experiments with only young nontechnical professionals to determine whether users welcome smartness through familiar communication devices such as PCs, TVs, and mobile phones. Paetz et al. [11] proposed an automated energy management system to test residents. These studies have contributed greatly to improve the completeness of a smart home service. However, as research on business and user perspectives for market revitalization was lacking, more studies are requisite to encourage the proliferation of smart home services.

The word "smart" has been used in various fields such as smart phones, smart TVs, and smart learning, including smart homes. Although it has a slightly different meaning in each concept, it generally means "intelligent," which can be interpreted as the concept of a weak level of artificial intelligence (AI). However, whether such a concept represents an intelligence service that can perfectly substitute the decision-making process of human beings requires debate. Humans in general will be reluctant to delegate all of the decision-making authority to machines considering their search for freedom, uncertainty, and distrust in technology. In addition, the level of smartness people demand would also vary depending on their individual characteristics and environment.

Some people have vague fears about intelligent and smart things. For instance, when AlphaGo beat a human in the Go game, some people had negative perspectives on AI because a computer can control or be detrimental to people. Thus, the "smart" that people want may entail a limited scope of intelligence which is under the control of human beings, unlike the theoretical point of view. Smart home service acceptance research has been active since the mid2000s. Most studies have extended the technology acceptance model (TAM) or the unified theory of acceptance and use of technology (UTAUT) and have focused on specific groups such as the elderly, the disabled, and patients. Leeraphong et al. [12] demonstrated that selfefficacy plays an important role in the acceptance of a smart home for the elderly.

Page-12 


\section{IMPLEMENTATION METHODOLOGY}

Raspberry $\mathrm{Pi}$ is using the Advanced Reduced Instruction Set Computing Machine (ARM) technology. ARM technology is used on the board which reduces cost, heat and power consumption. It is energy effective multi core CPU implemented as System-On-Chip (SoC) weighing 50gm and operates on $5 \mathrm{~V}, 700 \mathrm{~mA}$ power rating. This board is available in three models named A, B, B+. The B+ Raspberry Pi board is the latest version among them, and it runs on ARM11 processor with 512MB RAM operating at $700 \mathrm{MHz}$ frequency. It has SD card slot, which is used for booting the operating systems like Raspbian, Pidora, Raspbm. It has four USB2.0 ports to connect to the peripherals like mouse, keyboard and Wi-Fi adapter etc, making it as a full sized portable pocket computer. It also has an Ethernet port to connect to the network. GPIO ports are used to interface and control the LED's, switches, sensors and other devices. With the help of HDMI port, all kinds of monitors like LCD screens, projectors, TVs can be connected. In this board, some additional features like camera connector is available to interface camera and an audio jack. With all these features, Raspberry Pi is not just limited to single use, it can be used in many applications.

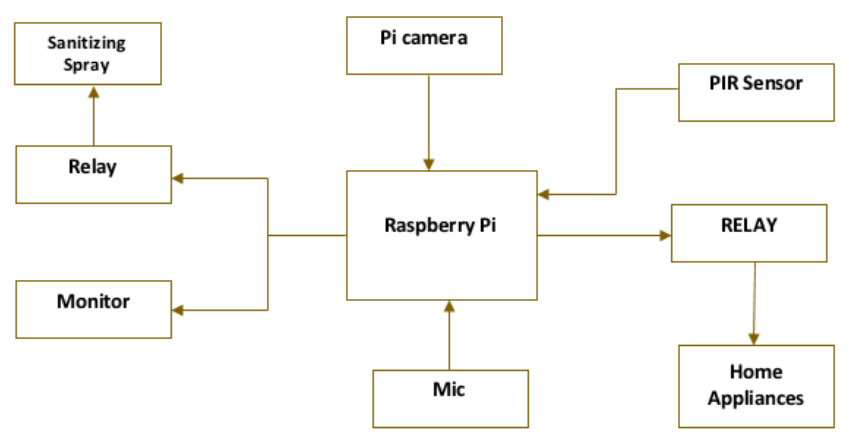

Figure 1. Block Diagram Raspberry Pi System

A Relay is electrically operated switches, which allow low power circuits to switch a Relatively high voltage or current on/off. For a relay to operate a suitable pull in and holding current should be passed through its coil. Relay coils are designed to operate from a particular voltage often its $5 \mathrm{~V}$ or $12 \mathrm{~V}$. The function of relay driver circuit is to provide the necessary current energize the relay coil, when a LOGIC 1 is written on the PORT PIN thus turning on the relay. The relay is turning off by writing LOGIC 0 on the port pin.

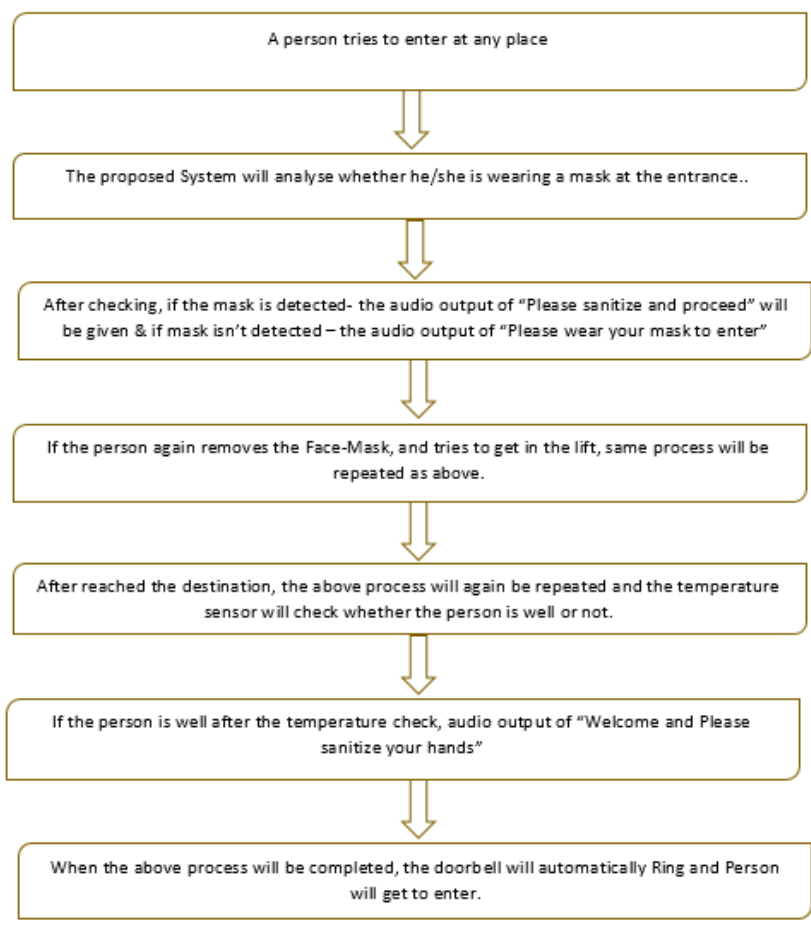

Figure 2. Flowchart of the working model

The term PIR is the short form of the Passive InfraRed. The term "passive" indicates that the sensor does not actively take part in the process, which means, it does not emit the referred IR signals itself, rather passively detects the infrared radiations coming from the human body in the surrounding area. The detected radiations are converted into an electrical charge, which is proportional to the detected level of the radiation. Then this charge is further improved by a built in FET and fed to the output pin of the device which becomes applicable to an external circuit for further triggering and amplification of the alarm stages. The PIR sensor range is up to 10 meters at an angle of +15 o or -15 o.LCD.

\section{CONCLUSION}

In the new world of coronavirus, multidisciplinary efforts have been organized to flatten the curve of transmission. The AI community has also been a part of these endeavours. In particular, developments for monitoring social distancing or identifying face masks have made-theheadlines. But all this hype and anxiety to show off results as fast as possible, added up to the usual. AI overpromising factor may be signalling the wrong idea that solving some of these use cases is almost trivial due to the mighty powers of AI. 


\section{REFERENCES}

[1] Y. Nakamura, Y. Arakawa, T. Kanehira, M. Fujiwara, and [11] C. Reinisch, M. J. Kofler, and W. Kastner, "ThinkHome: a K. Yasumoto, "SenStick: comprehensive sensing platform with smart home as digital ecosystem," in 4th IEEE International an ultra tiny all-in-one sensor board for IoT research," Journal Conference on Digital Ecosystems and Technologies, pp. 256of Sensors, vol. 2017, Article ID 6308302, 16 pages, 2017.View 261, Dubai, UAE, 2010, IEEE.View at: Publisher Site | Google at: Publisher Site | Google Scholar.

Scholar.

[2] V. Ricquebourg, D. Menga, D. Durand, B. Marhic, L. [12] P. Meso, P. Musa, and V. Mbarika, "Towards a model of Delahoche, and C. Loge, "The smart home concept: our consumer use of mobile information and communication immediate future," in 2006 IST IEEE International Conference technology in LDCs: the case of sub-Saharan on E-Learning in Industrial Electronics, pp. 23-28, Hammamet, Africa," Information Systems Journal, vol. 15, no. 2, pp. 119Tunisia, 2006, IEEE.View at: Publisher Site | Google Scholar. 146, 2005.View at: Publisher Site | Google Scholar.

[3] W. K. Edwards and R. E. Grinter, "At home with ubiquitous computing: seven challenges," in Ubicomp 2001: Ubiquitous Computing, pp. 256-272, Springer, Berlin, Heidelberg, 2001.View at: Publisher Site | Google Scholar.

[4] N. Balta-Ozkan, R. Davidson, M. Bicket, and L. Whitmarsh, "Social barriers to the adoption of smart homes," Energy Policy, vol. 63, pp. 363-374, 2013.View at: Publisher Site/Google Scholar.

[5] R. Lutolf, "Smart home concept and the integration of energy meters into a home based system," in Seventh International Conference on Metering Apparatus and Tariffs for Electricity Supply, pp. 277-278, Glasgow, UK, 1992, IET.View at: Google Scholar

[6] C. Kidd, R. Orr, G. Abowd et al., "The aware home: a living laboratory for ubiquitous computing research," in Cooperative Buildings. Integrating Information, Organizations, and Architecture, pp. 191-198, Springer, Berlin, Heidelberg, 1999.View at: Google Scholar.

[7] H. Andoh, K. Watanabe, T. Nakamura, and I. Takasu, "Network health monitoring system in the sleep," in SICE 2004 Annual Conference, vol. 2, pp. 1421-1424, Sapporo, Japan, 2004, IEEE.View at: Google Scholar.

[8] T. Koskela and K. Väänänen-Vainio-Mattila, "Evolution towards smart home environments: empirical evaluation of three user interfaces," Personal and Ubiquitous Computing, vol. 8, no. 3-4, pp. 234-240, 2004.View at: Publisher Site /Google Scholar.

[9] A. Leeraphong, B. Papasratorn, and V. Chongsuphajaisiddhi, "A study on factors influencing elderly intention to use smart home in Thailand: a pilot study," in The 10th International Conference on e-Business, Bangkok, Thailand, 2015.View at: Google Scholar.

[10] E. Park, Y. Cho, J. Han, and S. J. Kwon, "Comprehensive approaches to user acceptance of Internet of Things in a smart home environment," IEEE Internet of Things Journal, vol. 4, no. 6, pp. 2342-2350, 2017.View at: Publisher Site /Google Scholar. 